\title{
Agent-based models of language competition ${ }^{1}$
}

\author{
Xavier Castelló $^{1}$, Lucía Loureiro-Porto ${ }^{2}$, Maxi San Miguel $^{1}$
}

${ }^{1}$ Institute for Cross-Disciplinary Physics and Complex Systems, IFISC (CSIC-UIB), Campus Universitat Illes Balears, E-07122 Palma de Mallorca, Spain

${ }^{2}$ Department of Spanish, Modern Languages and Latin, Universitat Illes Balears, E-07122

Palma de Mallorca, Spain

\begin{abstract}
This paper uses computer simulations as a means of assessing two different models for the competition between two languages from the interdisciplinary perspective of complex systems. These models allow for the analysis of the role of bilingual speakers and they consider two of the basic factors determining the use of each language: their relative prestige and the language loyalty of their speakers. Here we assess the effect of these parameters in different social networks, with the aim of contributing to the understanding of the role of bilingualism and social networks in processes of language contact. We first present a qualitative analysis based on a simulation tool that we have designed, in order to visualize the dynamics of the models. Secondly, we consider a qualitative analysis of the role of complex networks, identifying mechanisms for the rapid extinction of a language and for situations of language segregation. Finally, we present a quantitative analysis which shows, counterintuitively, a transition from a final scenario of language maintenance to one of language shift as language loyalty increases. Other findings are: (i) that the scenario of language coexistence is reduced in the presence of bilingual agents; and (ii) that networks which allow for local effects reduce further the situations for which language maintenance is possible.
\end{abstract}

Keywords: agent-based models, language shift and revitalization, complex social networks, prestige, language loyalty

\section{Introduction}

Language competition (or language shift) is a wide-spread phenomenon that has caught the attention of numerous linguists and anthropologists interested in language contact and evolution (to cite just a few, Weinreich 1979; Hamers and Blanc 1989; Romaine 1989; Grenoble and Whaley 1998, 2006; Nettle and Romaine 2000; Fishman 2001; Bradley and Bradley 2002; Mufwene 2004, 2008). Different aspects of the phenomenon, such as the factors contributing to the survival of languages, strategies of linguistic policy, linguistic resistance of minority groups, etc. have been the subject of studies. Recently, language competition has also been studied by researchers working in fields other than linguistics, including mathematicians, computer scientists and physicists (Loreto and Steels 2007), following a recent trend that tries to systematize social behaviour and which stems from the assumption that social behaviour can be explained in terms of complex systems (Ball 2005; Castellano et al. 2009).

Complex systems are those displaying emergent phenomena in which the whole is more than the sum of the parts. In order to understand these phenomena we must not focus on 
the study of the role of the individual parts, but rather on the interaction between them. For example, the behaviour of a community of ants (a paradigmatic complex system) cannot be explained as the sum of the behaviour of each individual ant; an ant nest, rather, is the result of a collective phenomenon which primarily has to do with interaction between individual ants. Similarly one can understand the mind as an emergent phenomenon arising from the interaction of a thousand million neurons, and society as emerging from the interaction of many individuals. The scientific reductionist hypothesis does not, however, imply a "constructionist" one: entirely new properties appear at each level of complexity (Anderson 1972).

False assumptions of a common-sense kind include: i) complex behaviour implies complex causes, and ii) different systems behave differently. In fact, our current understanding of complex systems shows broad evidence that complex behaviour can arise from very simple interaction rules, and that collective behaviour shows universal features. As an example, a well known, simple model of residential segregation in the economics literature (Schelling 1978) is isomorphic to a version of the paradigmatic Ising model of magnetic phase transitions. It is in this context that simple models are proposed and used to study collective social behaviour: these models are not simplistic in the sense of lacking realism, but rather in that they aim to identify the relevant mechanisms for the phenomena under consideration. Complicating models with a more detailed description of interacting individuals does not lead to better understanding, since many of these individual features of the members of a community might well be irrelevant to its collective evolution. The importance of simple models is to understand the consequences of a relevant mechanism, establishing cause-effect relations beyond the observation of factual correlations. In this sense, these models are not aimed at being quantitatively predictive in practical situations, where several of these mechanisms often compete. Prediction does not necessarily imply understanding, and vice versa, a classical example being the predictive power of Ptolomeo's solar system description.

General sociological problems are considered from this viewpoint in the framework of Agent Based Models (Axelrod 2006): a set of agents interact under given rules, and the emergent global social behaviour is analyzed. The two basic ingredients of an agent-based model are the interaction mechanisms and the social network of interactions. One of these sociological problems is that of the emergence of consensus. The question is to determine when the dynamics of a set of interacting agents that can choose among several options (opinion, political vote, cultural features, etc.) leads to a consensus in one of these options, or when a state with coexisting social options prevails (San Miguel et al. 2005). In this paper we will address the problem of language competition from this perspective.

Along these lines of reasoning, the relationship between simple mechanism and emergent phenomena in problems of language competition was demonstrated in the pioneering work by Abrams and Strogatz (2003), who modelled the dynamics of language death on the basis of two simple parameters: prestige and volatility. As we will describe in Section 2, prestige refers to the relative social importance of the languages in contact, while volatility refers to the ease with which agents change the language they use. The model of Abrams and Strogatz, indeed, describes the situation of language contact as a complex system in which language death and maintenance result from the interaction among the individuals that form the society. Their model has inspired a series of scholars interested in shedding new light on the complex phenomena related to language maintenance and language competition (cf., for example, Schulze et al. 2008; Castelló et al. 2006; Castelló et al. 2008; Minett-Wang 2008).

As we will explain in Section 2, our concept of network is not far from that used in sociolinguistics from Milroy (1980) onwards, and whose importance in the vitality or 
disappearance of a language has been considered crucial (Milroy 2001: 5). However, little work has been done in terms of a quantitative approach to the relationship between social structure and language shift (cf. de Bot and Stoessel 2002: 2). It is our aim to contribute to filling this gap from an interdisciplinary point of view, a gap identified by Hamers and Blanc 20 years ago:

In order to capture the totality of this complex phenomenon [i.e. language contact] it is essential not only to examine it from different disciplinary viewpoints but also to integrate these various viewpoints both at the theoretical and the methodological level in order to design interdisciplinary models.... Studies of bilinguality and bilingualism are unidisciplinary, at most multidisciplinary, hardly ever interdisciplinary. (Our italics) (Hamers and Blanc 1989:257)

Thus, the interdisciplinary agent-based models we present here will help us understand and interpret the main mechanisms that operate in situations of language contact, and which result in emergent phenomena such as language endangerment, language coexistence and the emergence of new linguistic varieties.

The structure of the paper is as follows. Section 2 describes the main concepts used for the development of the model and links them to sociolinguistic phenomena. It also presents the two models that we will consider here, the Abrams-Strogatz model and the Bilinguals model. Section 3 presents a qualitative description of these models, using a simulation tool for this purpose, and also describes the main results found in different complex networks. Section 4 lays out the main quantitative results for the models. Finally, Section 5 offers some conclusions and points for discussion.

\section{Concepts and Models}

This section clarifies the terminology to be used, so as to avoid confusion which might arise from different uses of terms by those working in the area of language contact (2.1), and also describes the models that we will use in the study (2.2).

\subsection{Terminological concepts}

The concept language is understood in the field of language modelling as a discrete term, that is, the models presented in Section 2.2 do not include the implications of language (or dialect) continuum, as is commonly the case in variationist studies (Labov 1972; Trudgill 1990: 6). The principal reason for this decision is that our aim is to study language shift, rather than language variation and change.

The models, then, consider that there are speakers (or agents) of language A, speakers of language B and bilingual speakers of both languages A and B. It must also be noted that we are not studying language acquisition or competence, but rather, language use. The agents in the models will interact with one another according to their connections in a social network. In linguistics, the role of social network has been a hotly debated issue ever since Milroy's Language and Social Networks (1980). A good working definition of a social network is that provided by Hamers and Blanc (1989: 70): "the sum of all the interpersonal relations one individual establishes with others over time". In a typical social network diagram, individuals are represented by nodes, and social ties ${ }^{2}$ (i.e. relations between them) are represented by lines joining two nodes. These relationships can be illustrated as in Figure 1:

\section{INSERT FIGURE 1 ABOUT HERE}


Social networks not only account for the relations between members of a community; it has also been shown that "variation in the structure of the different individuals' personal social networks will systematically affect both the vitality of the community language and the speech community's vulnerability to language shift" (Milroy 2001: 5). Attributing such an important role to social networks in the maintenance and survival of languages was revolutionary at a time when community structure was not taken into account at all in sociolinguistics, other phenomena, such as institutional, socio-political or economical factors, being seen as more prominent in the study of language shift.

Following Milroy's pioneering work, almost every study on sociolinguistics came to consider in some way the role of social structure, and this was reflected in the International Journal of the Sociology of Language devoting an entire volume (edited by de Bot and Stoessel) to the empirical analysis of the role of social networks in several bilingual communities in 2002.

Networks are also of great interest to other disciplines. For example, different types of networks have been proposed to account for social interaction, of which we highlight five in this paper. Firstly, fully connected networks are those in which each agent is connected to all other agents (see Figure 2-left). To be exact, there is no network as such, but instead a population of agents who are totally connected. Secondly, we will consider random networks (see Figure 2-right), in which each agent is connected only to a given number of randomly chosen agents: their neighbours. Thirdly, in regular lattices agents are distributed periodically in space (see Figure 3-left), and each agent has the same number of neighbours. Both random networks and regular lattices introduce what is known as local effects: agents do not interact with every other agent in the network but only with their neighbours. Notice that one main difference between regular and random networks is that, in random ones, the position of a node is independent of the position of the other nodes. Fourthly, small world networks (see Figure 3-right) lie between regular lattices and random networks: they have a local substrate (just like regular lattices) and at the same time they contain long range interactions which make the social distance between any two agents very short (characteristic of random networks). The small world phenomenon, empirically observed by the first time by Travers and Milgram (1969), was modelled by Watts and Strogatz (1998) using a very simple algorithm. Finally, we focus on networks with community structure (see Figure 4), which are characterized by the existence of communities, that is, sets of nodes more connected to one another than to the rest of the network (Wasserman and Faust 1994). The presence of communities is one of the main features of real social networks. Generally, this topological signature affects dynamical models regarding very different social problems, from the emergence of cooperation (Lozano et al. 2008) to the spread of information (Onnela et al. 2007).

\section{INSERT FIGURE 2 ABOUT HERE INSERT FIGURE 3 ABOUT HERE INSERT FIGURE 4 ABOUT HERE}

In the models we study, speakers (agents) will use language A, B or both (i.e. agents may have three states: $\mathrm{A}, \mathrm{B}$ or $\mathrm{AB}$ ), and this will depend on their relations in the social network. There are other factors that play a prominent role in the choice of a language in the members of a bilingual community. The first of these is controversial: the prestige of one language over another, or what is effectively the same thing, the prestige of a community using one language over another community using a different language. 
The role of prestige in language choice has been a commonly discussed factor of language change since Labov's Sociolinguistic Patterns (1972), and can be defined as "the positive evaluation of linguistic forms" (Swann et al. 2004: 249). In the field of language competition, it is usually assumed that speakers of the less prestigious language will shift to the use of the more prestigious one so as to achieve social success. However, it is not always easy to determine which of the two languages is more prestigious, because there are two opposing / complementary types of prestige: overt and covert prestige, a term first coined by Trudgill (1974).

The meaning of overt prestige is clear: a language is objectively more prestigious as its presence in education, religion, administration and the media is stronger. Covert prestige, however, is much more subjective, it has 'local' connotations and refers to positive attitudes towards a language which may be official or non-official and, therefore, with no overt prestige (cf., for instance, Holmes 2001: 345; Swann et al. 2004: 249).

It is precisely this dichotomy that has made authors such as Mufwene (2008: 46-47, for example) reject the role of (overt) prestige in language contact. In his view, if prestige actually played a role in language choice, stigmatized linguistic varieties such as Appalachian English, AAVE or the creole Gullah would be severely endangered; in fact, they are not. Mufwene's account of the survival of these linguistic varieties is based on a individual's sense of belonging to a given minority community. Thus, instead of the term prestige, Mufwene prefers the term market value of a language (personal communication), i.e. speakers do not select language A or B depending on their official status, presence in the media or in administration, but depending on the momentary and local value of that language.

Another term used in the same vein as covert prestige is language loyalty, which might also be called 'local' prestige, that is, the positive attitude speakers have towards a stigmatized language on the basis of ethnicity, or, perceived ethnolinguistic vitality (cf. Hamers and Blanc 1989: 163).

Prestige, understood in the narrow sense of overt prestige, is one of the key factors in the models of language competition we study here. In them, prestige is coded as $s$ (following the conventions used by Abrams and Strogatz 2003, $s$ standing for the term status). ${ }^{3}$ As such, prestige in the models is a property of the language (which, of course, can be the result of socio-cultural situations).

Nevertheless, the models also account for covert prestige or language loyalty, by means of a parameter which we call volatility (coded as $a$ in the model), which might be defined as the propensity speakers have to shift languages. It is well known that in social groups not all speakers are equally volatile, i.e. not all of them show the same degree of accommodation $^{4}$ (a term suggested by Mufwene, personal communication, cf. also Mufwene [2001: 26, 32-33, 2008: 15-16]). Volatility will prove to be a crucial component in the explanation of how languages in contact compete and of how new linguistic varieties emerge (Sections 3 and 4). Notice also that volatility is not a property of the language (as prestige is), but a property of the interaction among individuals. As we will see, all agents in the models exhibit the same degree of volatility, which may be of three sorts: (a) neutral volatility, which implies that agents shift languages by a process of imitation ${ }^{5}$, (b) high volatility, which implies a quicker shift than that found in a simple process of imitation, and (c) low volatility, which implies a slower shift than that found in imitation. Basically, low volatility may be caused by two factors: on the one hand, agents may be reluctant to shift languages because of language loyalty (i.e. the language may have covert prestige); on the other hand, agents may simply decide not to shift languages if the two varieties are typologically close enough (cf. Mira and Paredes 2005). In turn, high volatility may be caused by a wish to accommodate to the interlocutor's language. 


\subsection{Models of language shift: Abrams-Strogatz and Bilinguals models}

In the present study we look at two models of language competition: the one proposed by Abrams and Strogatz (2003), which considers two languages in competition, and an extension of this model inspired by Minett and Wang's $(2005,2008)$ proposal, in which bilingual agents are taken into account: the Bilinguals model. $^{6}$

Abrams-Strogatz's model stems from the assumption that prestige is one of the two linguistic parameters in cases of language shift, as shown in the following equations:

$$
\begin{aligned}
& p_{B-A}=s \cdot\left(\sigma_{A}\right)^{a} \\
& p_{A-B}=(1-s) \cdot\left(\sigma_{B}\right)^{a}
\end{aligned}
$$

Plainly, the probability $\left(p_{B->A}\right)$ that one speaker of language B shifts to language A depends on the prestige $(s)$ of $\mathrm{A}$, the density of speakers of $\mathrm{A}\left(\sigma_{A}\right)$ in the vicinity of that agent, and the volatility $(a)$ of those speakers. The volatility parameter can take any value above zero. ${ }^{7}$ In turn, the values of $s$ range from 0 to 1 , so that if the prestige of language A is $s$, that of language $\mathrm{B}$ is $1-s$, as seen in the second equation, which shows the probability that a given speaker of A becomes a speaker of B. Notice that what is relevant for the modelling is the relative prestige between languages, rather than the absolute value of $s$. In particular, two languages with equivalent prestige are modelled by $s=0.5$. The more neighbours use language $\mathrm{A}$ and the more prestigious language $\mathrm{A}$ is, the higher the probability that a given speaker of $\mathrm{B}$ will shift to A. In Abrams and Strogatz's view, this would explain the threat represented by Spanish to Quechua in Huanuco (a region in Peru), or the threat by English to Scottish English. Their model represents the point of departure of the second model that we present in this paper, namely Bilinguals model.

The Bilinguals model takes advantage of the parameters used by Abrams and Strogatz, and in addition introduces bilinguals (i.e. $\mathrm{AB}$ agents) as an intermediate step between monolingual A and monolingual B, as seen in Figure 5.

\section{INSERT FIGURE 5 ABOUT HERE}

The mathematical formulation of the model is, then, an extension of AbramsStrogatz's, as follows:

$$
\begin{aligned}
& p_{A \rightarrow A B}=(1-s) \cdot\left(\sigma_{B}\right)^{a} \\
& p_{B \rightarrow A B}=s \cdot\left(\sigma_{A}\right)^{a} \\
& p_{A B \rightarrow A}=s \cdot\left(1-\sigma_{B}\right)^{a} \\
& p_{A B \rightarrow B}=(1-s) \cdot\left(1-\sigma_{A}\right)^{a}
\end{aligned}
$$

Notice that the probability of a change from monolingual A to bilingual AB depends only on the density of monolingual $\mathrm{B}$ speakers, while the probability of change from bilingual $\mathrm{AB}$ to monolingual $\mathrm{B}$ depends on the density of speakers using the language to be adopted, including bilinguals. It is important to stress that a change from language $\mathrm{A}$ to language $\mathrm{B}$, or viceversa, always implies an intermediate step through the bilingual AB state. The introduction of bilinguals leads to very interesting results as far as the maintenance of a language is concerned, as we will see in Sections 3 and 4.

Work by Abrams and Strogatz (2003) and Wang and Minett (2005) presupposes that populations are fully connected, that is, each speaker of the community interacts with all the others. This is not, however, a realistic assumption. As we know, in real life individuals interact only with those individuals in their social network. Our contribution here, then, lies in 
the introduction of social networks of interaction and their effects in the possible sociolinguistic scenarios of endangerment, coexistence, segregation and language death. Moreover, we analyze systematically the role of prestige and volatility in the emergent behaviour observed in both models.

\section{Exploration of the models}

\subsection{Visualizing the dynamics of language competition: a simulation tool}

As a means of introducing our work, we offer a simulation tool or applet available online that visualizes the dynamics of language competition (see Figure 6 below). ${ }^{8}$ This tool offers a visual representation of the Abrams-Strogatz's model and the Bilinguals model, with agents placed in a regular lattice in which each agent has four neighbours (see Figure 3-left above). Thus, in Figure 6 we observe how the agents are said to speak languages represented by black or grey (in the Abrams-Strogatz's Model) and black, grey or white (in the Bilinguals Model), in which white agents stand for bilingual speakers, that is, agents who use (rather than know) both languages. The sum of the densities of agents speaking language A, B and bilinguals is normalized to one, and random initial conditions establish that in the Abrams-Strogatz's Model around $50 \%$ of the agents speak each language, while in the Bilinguals Model, around $33 \%$ of the agents speak either black, grey or are bilinguals (white agents).

\section{INSERT FIGURE 6 ABOUT HERE}

The simulation tool allows the user to change the values of $s$ (overt prestige) and of $a$ (volatility, described above as language loyalty). In the applet, the values of $s$ range from 0 to 1 and those of $a$, from 0 to 5 . It should be noted that the default initial conditions stem from a situation in which two socially equivalent languages exist, hence the default value of $s$ is 0.5 . The default value of volatility $(a)$, in turn, is 1 , which stands for neutral volatility (i.e. imitation) as described above. Counter-intuitively, any value below 1 stands for increasingly high volatility, while any value above 1 stands for increasingly low volatility. When the "start" button is pressed, the agents in both models begin to interact with each another and will shift languages depending on these conditions, which can be observed by the change in their colour.

When interpreting the simulations in our applet, the value of the category time should be handled with care. The interaction among the agents in the network and the choice they make as for the language they use will allow us to analyze language maintenance in a given period of time. However, the numerical value of time in the applet does not correspond to an actual period (measured in months, years, etc.), but refers to the average number of interactions that a given individual has maintained with their neighbors in the network, and hence it merely allows us to make a qualitative comparison of the temporal effects of the parameters. That is, the model allows us to state that language death occurs earlier under certain conditions (i.e., different parameter values) than in others, but it does not tell us the number of years a given language may survive.

One of the most interesting aspects of this simulation tool is that users may change the values of prestige $(s)$ and volatility $(a)$ in real time so as to observe their effect on the formation of linguistic domains and on the survival or death of the languages.

The following subsections present the results from the models, which, as said in the introduction, allow for no prediction in sociolinguistic terms, but do help us understand the mechanisms underlying language shift. For this reason, all the references to real 
sociolinguistic situations offered here are not intended to validate the model, but rather to provide illustrative and qualitative interpretations of the results presented in this paper.

\subsection{Effects of bilingual agents in the case of socially equivalent languages}

As already mentioned, the main difference between the Abrams-Strogatz model and the Bilinguals model involves the presence of bilingual speakers, and this has important effects on language dynamics, as we will describe below.

In this section, we consider socially equivalent languages $(\mathrm{s}=0.5)$ and neutral volatility $(a=1)$. The first interesting finding, as far as the role of bilinguals is concerned, is the low proportion of bilingual users (in the Bilinguals model, see right panel of Figure 7, the density of bilingual speakers is just 3\%). This implies that even in a bilingual community in which two equally prestigious languages coexist, speakers will either use one or the other, with only a few of them using both languages. Thus, the qualitative conclusion we can draw from the Bilinguals model is that few speakers actually use both of the languages available in their social group, but rather select one.

Secondly, bilinguals (only present in the Bilinguals model) prove to be central agents in the formation of clearly defined linguistic domains in the network, placing themselves at the boundaries between monolingual domains. As seen in Figure 7, these domains are not formed in the absence of bilinguals.

\section{INSERT FIGURE 7 ABOUT HERE}

The formation of monolingual regions of speakers of one language in areas surrounded by bilingual speakers who are also in contact with monolingual islands of speakers of another language may be qualitatively compared to the situation of Galician (a Romance language spoken in NW Spain). According to Rojo-Sánchez and González-González (1995), the monolingual use of this language is mainly circumscribed to rural areas, while the monolingual use of Spanish is only found in urban areas. Likewise, originally monolingual speakers of Galician become bilingual users as they move to urban areas.

In the case of socially equivalent languages and neutral volatility, the final scenario observed in both models is that of dominance of one language and extinction of the other. Due to the equal prestige of the languages, extinction of language A and language B take place with the same probability.

\subsection{The roles of prestige and volatility. Language endangerment, language resilience and} emergence of new linguistic varieties

Apart from the role of bilingualism, the roles of the parameters prestige ( $s$ in the model) and volatility $(a)$ lead to some very interesting situations of language contact.

The parameter prestige has essentially two possible types of values in the model. The first stands for that situation in which both languages are socially equivalent $(s=0.5)$, i.e. both can be used in all types of social situations, as considered above. The second situation is that in which one of the languages is more prestigious than the other $(s \neq 0.5)$. Given this condition, the less prestigious language is bound to disappear in a shorter period of time compared to the case of socially equivalent languages. A sociolinguistic situation which could illustrate this result concerns Algherese, an old Catalan variety spoken in an area in North-West Sardinia. This language is in contact with the state language, Italian, and the island language, Sardinian, and its prestige (or market value) appears to be very low, since it is not present in education, etc. ${ }^{9}$ This seems to lead to an imminent death and, in fact, the latest sociolinguistic data, from 2004, reflect a situation in which Algherese is actually undergoing severe language endangerment, since its (very low) use is restricted to the home, and to only $7.2 \%$ of the 
people in the region (Generalitat de Catalunya 2004: 28). In addition, students of secondary or higher education do not use Algherese with their classmates (Generalitat de Catalunya 2004: 31). The data suggest that the overt prestige of Algherese is very low, and consequently the disappearance of this language appears to be imminent. ${ }^{10}$

Our applet also allows us to change the value of prestige in real time, so as to effect a reverse of language shift (cf. Chapel et al. 2010). Thus, if we begin with a situation in which one of the languages is more prestigious than the other, and this latter, as a consequence, is endangered (e.g. $s=0.7$ ), the value of $s$ may be restored to a more balanced situation $(s=0.5)$, and this brings about the revitalization of the endangered language. This appears to have been the case of Quechua, which was endangered before it became co-official in Peru, at which point it gained standardization and began to be used in the media, education, etc. (Baker and Prys Jones 1998: 152). In fact, the increase in the prestige of Quechua has had a clear effect on its frequency of use even in urban communities (cf. Manley 2008). Further qualitative illustrations of the effects of prestige in situations of language contact can be seen in the Dominican Republic, where the non-prestigious Haitian Creole is in competition with the prestigious Spanish (see Jansen, this issue).

The second parameter included in both models is volatility ( $a$ in the applet), which has been compared to language loyalty. As already noted, neutral volatility is reached when $a=1$, while high and low volatility are reached when $a$ 's value is, respectively, either below or above 1. Both high and low volatility yield results that can be seen as interesting sociolinguistic situations, and these are examined in the paragraphs that follow.

A particularly interesting feature of the role of low volatility in the models is that it operates against the effect of prestige, up until now seen as unassailably powerful. Even in an extreme situation, where the prestige of one of the languages is 0.1 (the most prestigious language being 0.9), if the system is not volatile (i.e., if $a=5$ ) the disappearance and death of the less prestigious language occurs; the extinction, however, is delayed for very long periods of time, these being longer as the parameter $a$ increases. At the same time, if language policies were introduced in favor of the less prestigious language before it died, these would need a longer period of time to show their effects on the community, because speakers would be reluctant to shift their languages (see Chapel et al. 2010). This would mean that in a nonvolatile system actions in favor of one of the languages would take longer to show its effects, although at the same time, such a situation would mean that more time was available to pursue language policies. Thus, it could be said that in these conditions a language would be resilient, that is, it would have the capability of recovering from a threatening situation.

A possible illustrative example of a resilient language might again be the case of Galician, which survived forty years of pressure exerted by the overtly prestigious Spanish, the language of the government, the army, school, administration, church, etc. under Franco's dictatorship (from 1936 to 1975$)^{11}$ in which the use of Galician as a means of official communication was forbidden (Monteagudo and Santamarina 1993: 126). During these forty years, Galician remained a language of rural areas, while Spanish was the official language. The lack of interest in the use of Galician by Spanish-speaking members of the socially empowered classes, and the unwillingness of Galician-speaking peasants to use Spanish, may be interpreted as a case of the low volatility of a community in which, on other levels, shifting social class was hardly possible (see Ayestaran and de la Cueva 1974 for details on the use of Galician and Spanish among Galician housewives at the end of the dictatorship). Users of Galician in contact with the monolingual Spanish community would shift to Spanish in specific contact contexts, but shift back to Galician within their own group. This bilingualism in a non-volatile society may have also played a role in the survival of Galician. Indeed, our applet shows that the presence of bilingual agents, in the case of non-volatile systems, contributes to the delay in the extinction of the endangered language, while in the Abrams- 
Strogatz Model it disappears a lot earlier in time, as seen in Figure 8 (notice that the time of extinction of language A in Abrams-Strogatz's model is 2197, while in the Bilinguals model at time 4274 both languages still coexist).

\section{INSERT FIGURE 8 ABOUT HERE}

The second interesting role of the parameter volatility in the models is seen in the other extreme situation, that is, when the system is highly volatile ( $a=0.1$ in our applet stands for the most volatile situation). Here agents shift languages constantly, (almost) irrespective of the language used by their interlocutors. In the real world, these would be speakers who show a low degree of attachment to any language (language loyalty is very low for both linguistic groups). Counter-intuitively, the models show that high volatility prevents language death, because it implies that no speaker gets attached to either language in the community, so both are equally used through time, as seen in Figure 9.

\section{INSERT FIGURE 9 ABOUT HERE}

For the Bilinguals model, Figure 9 shows that after a considerable amount of time (more than 8000 interactions) the density of speakers of each of the two languages of equal prestige $(s=0.5)$ in a highly volatile system $(a=0.1)$ is roughly the same $(0.368$ and 0.392 , respectively). In addition, we can also see that, for the first time, the density of bilingual speakers ( $\mathrm{AB}$ agents) is comparable to that of each monolingual group (0.241). This is so because, for the first time, they do not act as bridges between monolingual communities, but are found scattered throughout the lattice. We now offer an interpretation for this unexpected finding.

In highly volatile systems, such as the ones seen on both sides of Figure 9 (i.e. in both Abrams-Strogatz and the Bilinguals' models), all agents speak A and B equally often and they also prove to be $\mathrm{AB}$ speakers at a similar rate. Thus, in a way, we could say that all agents are in essence bilingual users, because they actually use both languages and they change language use constantly. Although the model does not account for the duration of social interactions, the high frequency with which agents switch languages leads to an interesting interpretation: agents are switching languages within the same speech act. They are, from a sociolinguistic point of view, speakers of mixed linguistic varieties such as those that fall under the category of code-mixing or code-switching (see Poplack 1980; Heller 1988; Auer 1998, among many others).

This interpretation could also be qualitatively illustrated with a real sociolinguistic interpretation. Gibraltar, a British colony on the south of the Iberian Peninsula, has had English as its official language for almost three centuries now (since 1713, Treaty of Utrecht, after the War of the Spanish Succession). At the same time, Spanish was never abandoned as a primary means of communication among the people on the Rock, as well as with their neighbours across the border in Spain. During all this time, then, English and Spanish have coexisted as languages A and B in a community in which speakers have never been afraid of shifting languages in order to adapt to circumstances (cf. Levey 2008: 80). In general, Gibraltarians have a good command of English and of Spanish, but over the course of time, due to the constant contact and alternation of these two languages, speakers have developed a new code-mixing and code-switching variety (see Auer 1999 for a clear definition of these terms). This variety is known as Yanito or Llanito (cf. Moyer 1993, 1998) and its existence has never represented a threat to either English or Spanish (cf. Levey 2008: 81); on the contrary, the three linguistic varieties coexist harmoniously on a small rock with around 30,000 inhabitants, and alternation between them is very likely, as reported by one of Levey's 
(2008) informants: "I've got about two or three different groups of friends and some of them speak just English and some of them speak a mixture but I think that does tend to happen a lot [...] I have no problems with Spanish or English. I just adapt" (2008: 80).

The emergence of new varieties due to language contact is a hot topic in sociolinguistics, and we believe that our work can qualitatively contribute to a better understanding of the underlying factors here. The birth of varieties such as Spanglish (codemixing of Spanish and English in the US by Spanish-speaking immigrants, cf. Lipski 2008) can roughly be considered through the models described in our applet. The linguistic volatility of the immigrants in the US must be very high, since they have to use English and Spanish alternatively depending on who their interlocutor is. This high degree of volatility, we suggest, may have been the trigger for the development of varieties involving codeswitching. ${ }^{12}$

Volatility, then, proves itself to be a key parameter in the models, since, on the one hand, it may diminish the effects of prestige (which has often been overestimated in sociolinguistics, cf. Mufwene 2003), and, on the other hand, a slight alteration of its numerical value can produce interesting changes of collective behaviour, which we will address quantitatively in Section 4.

\subsection{Qualitative results in complex networks: small-world networks and networks with community structure}

In the previous section we have begun to gain some understanding of the behaviour of the models in regular networks, with a special emphasis on the role of prestige and volatility parameters. We now turn to the effects of complex networks, which include some of the main features found in real social networks: the small world phenomenon and the existence of communities (see Section 2). We restrict our results here to the case of languages with equivalent prestige $(\mathrm{s}=0.5)$ and neutral volatility $(\mathrm{a}=1)$.

We will begin by addressing the effect of long range interactions throughout the social network (favoured by new technologies, increasing mobility, etc.), by studying small-world networks (Watts and Strogatz 1998). In Figure 10, we show snapshots of the Abrams-Strogatz and the Bilinguals model in a small world network which has been projected in a twodimensional space. ${ }^{13}$ Initially, we have a domain of language A surrounded by the majority language B. In the AS-model, we do not observe substantial differences compared to the results in a regular network (Figure 7, left panel). This initial domain of language A also diffuses throughout the network, without the emergence of clearly defined language domains. We see substantial differences only when we consider bilingual agents. In the Bilinguals model, the domain, similar to the ones emerging in regular networks (see Figure 7, right panel), splits into smaller ones, which shrink fast, resulting in the extinction of language A. This is due to the effect of long range connections which connect the agents inside the Alinguistic domain with the majority surrounding language B. Therefore, the addition of bilingual agents in the model, together with an increasing number of long range interactions, results in a faster path to extinction of one of the languages. For a complete analysis of the Abrams-Strogatz and Bilinguals models in small-world networks see Castelló et al. (2006).

\section{INSERT FIGURE 10 ABOUT HERE}

We have also looked at networks with a community structure (see Section 2). Similarly to what we found in small-world networks, the community structure does not affect the ASmodel substantially (Figure 11-left): language domains are shown to diffuse through different communities easily. Instead, in the Bilinguals model we observe simulations (Figure 11-right) in which very important correlations between language domains and community structure 
emerge: once a language is spoken in a community, this language becomes the one used by the community in the long term, with bilingual agents placed in the nodes of the network which join different linguistic communities. Slowly, the communities of the minority language change to the language which is becoming dominant. However, minority languages, which otherwise would face extinction very quickly, can survive for very long periods of time in isolated communities which are loosely connected to the rest of the network (see Figure 11right, $\mathrm{t}=1000$ ). Notice that this coexistence scenario differs radically from the one found in Figure 9 (code-switching) for the analysis of the qualitative findings in regular networks. There, coexistence was triggered by the high volatility of the agents, and it was of a "mixed nature", with all agents changing language over time. In networks with community structure instead, we find segregated coexistence, with language domains correlated with community structure. Situations of language segregation qualitatively comparable to the one just shown are well known in sociolinguistics, as is the case of Pennsylvania Dutch, an old variety of German that has survived for centuries in the U.S., owing to the segregated nature of the community that speaks it (among which the best known are the Amish people). For a complete analysis of the Abrams and Strogatz and Bilinguals models in networks with community structure see Castelló et al. (2007).

\section{INSERT FIGURE 11 ABOUT HERE}

\section{Formal analysis and quantitative results of the models}

In the previous section we have explored in detail the simulation applet, which we designed to visualize the two language dynamics models under study here, understanding qualitatively the role of the parameters of the models, and the one played by bilingual agents in regular networks. Moreover, relevant qualitative results in complex networks (small world networks and networks with community structure) have also been discussed. In this way, we have given an intuitive overview of the possible sociolinguistic scenarios provided by the models: coexistence of the two languages (mixed or segregated); extinction of one language and dominance of the other.

In this section we aim to move beyond this qualitative study, in order to provide a formal analysis of the scenarios described above. We present a brief summary of the quantitative results associated with the Abrams-Strogatz and the Bilinguals models, taking into account also the effects of the social network of interactions. We first present the results for the Abrams-Strogatz model, then discuss the consequences of introducing bilingual agents (Bilinguals model).

\subsection{Fully connected networks}

We begin by analysing a fully connected network, in which every agent is connected to every other agent in the network. Broadly speaking, there is in fact no network, but rather a population of agents who are totally connected (see Figure 2-left). This is the easiest case to study mathematically. For a complete analysis of the models in fully connected, random, and regular networks see Vazquez et al. (2010) and Castelló et al. (2011).

For the models in a fully connected network, one can mathematically determine the values for the fraction of speakers of each of the languages which, once reached, remain constant (these values are called fixed points). As we explain below, fixed points can be used to describe sociolinguistic situations of language coexistence and language dominance (and extinction). Fixed points depend on the parameters prestige $(s)$ and volatility $(a)$, and they can be stable or unstable. Stable fixed points correspond to situations in which if there is a slight change in the densities of speakers, the dynamics comes back to the same state; in other 
words, the dynamics tends to the fraction of speakers given by the stable fixed point. On the contrary, unstable fixed points correspond to those from which small changes make the system move away from that situation.

The Abrams-Strogatz model has three fixed points. Two of them, which are always present, correspond to the extinction of one language and the dominance of the other, i.e., they represent situations in which all the agents speak either language $\mathrm{A}$ or language $\mathrm{B}$. The third fixed point corresponds to a situation of language coexistence, i.e., it contains both speakers of language A and speakers of language B.

The stability or instability of the fixed points can be illustrated by a stability diagram (Figure 12-left), which gives us information about which is the final scenario of the system (coexistence, or dominance of one of the languages) depending on the parameters of the model $(s$ and $a$ ).

\section{INSERT FIGURE 12 ABOUT HERE}

On the one hand, the diagram (Figure 12-left) shows how for the Abrams-Strogatz model in the high volatility regime $(\mathrm{a}<1)$ we obtain a situation of coexistence of the two languages. Indeed, we have a population of agents switching from one language to another, and achieving a situation of language maintenance (this can be interpreted as a situation of code-switching like that of Yanito in Gibraltar, cf. Section 3.3). On the other hand, we observe a low volatility regime $(\mathrm{a}>1)$ in which the final scenario is one of the dominance of one language and the extinction of the other (this can be illustrated by the endangered situation of Algherese in North-West Sardinia, cf. Section 3.3). It is important to stress that both languages can become dominant, independently of prestige. ${ }^{14}$ Besides, in this scenario increasing the parameter $a$ results in an increasing delay in reaching such an extinction (this corresponds to the case of Galician, cf. Section 3.3). In summary, the fact that agents are highly volatile (do accommodate easily to the other language) favours language coexistence, while, on the contrary, low volatility agents favour the extinction, although in the long term, of one of the languages. Notice that instead of a smooth continuous change of behaviour, a sharp transition from coexistence to dominance is found at volatility $a=1$. These abrupt changes of behaviour are characteristic of complex systems.

In the Bilinguals model, an equivalent stability diagram is obtained (Figure 12-right). However, the critical value in which the transition from a coexistence to a dominance scenario occurs is found to be at the value $a=0.63$ (Vazquez et al. 2010). Compared to the AbramsStrogatz model, where this happens at $\mathrm{a}=1.0$, we find a reduction of the area in the stability diagram corresponding to coexistence. This is a significant result of the model, as it implies that in order to achieve a situation of coexistence of two competing languages, agents with higher volatility are needed, that is, agents who accommodate easier to the other language. In other words, the presence of bilingual agents is seen to hinder language coexistence.

Finally, notice that both models exhibit the same qualitative behaviour (transition from coexistence to dominance at a given value of the parameter $a$ ), but that the transition happens to be shifted to smaller values of $a$ in the presence of bilingual agents.

\subsection{Local effects: Random networks and back to regular lattices}

As discussed in Section 2, social networks are of great importance in sociolinguistics and play a central role in situations of language contact. Thus we now move from considering an all-toall connected society (fully connected network) to random networks (Figure 2-right) and regular lattices (Figure 3-left). In this way, local effects, that is, the fact that agents do not speak to every other agent but only to their neighbours in the social network, come into play. In random networks every agent is connected only to a given number of randomly chosen 
neighbours, $\mu$ (see Figure 2). In Figure 13 we see the stability diagram corresponding to random networks for the Abrams-Strogatz model.

\section{INSERT FIGURE 13 ABOUT HERE}

Comparing Figure 13 to the one corresponding to a fully connected network (Figure 12-left), we find that two new regions appear (region A and region B). In these regions only domination of the most prestigious language is stable. Moreover, these regions become larger as the number of neighbours decreases, as shown in Figure 13 when comparing networks with $\mu=3$ and $\mu=10$ neighbours respectively. Therefore, the area corresponding to coexistence (region $\mathrm{C}$ ) is increasingly reduced when the number of neighbours, $\mu$, decreases. This is probably due to the fact that, in networks with a small number of neighbours and for languages with different prestige $(s \neq 0,5)$, agents using the more prestigious language have less (or no) contact with the minority using the endangered one (in comparison to the case of a fully connected network, in which every agent is connected to every other one, and hence the minority language is always visible to all the agents in the network). Finally, similarly to what is found in fully connected networks, we find a region corresponding to dominance (region D), where both languages can become dominant, independently of prestige.

Briefly, local interactions (finite, small numbers of social neighbours) are shown to prevent situations of language coexistence and to reinforce the role of prestige, in the sense that, as local effects become stronger, we find more situations in which the more prestigious language becomes the one spoken by all the agents in the network (regions A and B become larger).

When considering regular networks like those in Section 3 (4 neighbours per agent), the stability diagram for the Abrams-Strogatz model is qualitatively the same. However, compared to a random network with the same number of neighbours $(\mu=4)$, regions A and B become even larger, and therefore the region corresponding to a coexistence scenario (region C) becomes even smaller. Therefore, regular connectivity is responsible for an additional difficulty in achieving language maintenance.

Let us now focus in the Bilinguals model. In a random network, the picture is similar to the one presented for the Abrams-Strogatz model (Figure 13). However, we find how the lines separating the different regions are shifted to even smaller values of the volatility parameter $a$, compared to the case of a fully connected network. In the case of socially equivalent languages $(\mathrm{s}=0.5)$, the transition from coexistence to dominance happens to be at volatility $\mathrm{a} \approx 0.3$ (compared to the value $\mathrm{a}=0.63$ in fully connected networks). In a regular network, this transition is at an even smaller value: $\mathrm{a} \approx 0.16$. In this way, as we have previously found in fully connected networks (Figure 12), the presence of bilingual agents is an additional factor which hinders language coexistence in both random and regular networks.

Summing up, in this section we have studied the different final scenarios of the Abrams-Strogatz and the Bilinguals models, analyzing the transition from coexistence to dominance/extinction as we increase the parameter $a$. We have found that bilingual agents, the reinforcement of the locality of the network, and regular connectivity reduce the scenario of language coexistence progressively (region $\mathrm{C}$ in Figure 13). Notice that the findings in this section illustrate the importance of modelling processes of language contact beyond the simple approximation of fully connected networks, highlighting the key role of social networks in the final outcomes of the models. 


\section{Conclusions}

In this study we have discussed an analysis of two agent-based models of language competition, the Abrams-Strogatz model and the Bilinguals model, with the aim of analyzing how, within the framework of these models, language shift is affected by prestige and volatility (parameters of the models), the structure of the social network, and the presence of bilingual agents (understood as users of the two available languages). We have shown that it is possible to build simple models that account for the complex behaviour observed in situations of language contact: from the formation of linguistic domains and the emergence of new linguistic varieties, to the well-known scenarios of language coexistence, language segregation, and language extinction. As we pointed out in the Introduction, the aim of our paper is not predictive, but seeks to uncover the causal relations between social mechanisms and their consequences, improving in this way our understanding of sociolinguistic behaviour, which, in our case, refers to the adoption of one of the two languages available in a given community.

Our main finding concerns the identification of the parameter $a$ in the models (which we term 'volatility') as a key factor in the transition from a scenario of coexistence (language maintenance) to one of dominance of a language (language shift). In this sense, volatility fights back against the effects of the parameter $s$, prestige, whose role has traditionally been claimed to be of paramount importance in favouring the diffusion of the most prestigious language. Our analysis shows, in fact, that volatility (sociolinguistically interpreted as language loyalty) is the factor that triggers the transition from coexistence (language maintenance) to dominance (language shift). This claim is in accordance with previous studies which challenge the centrality of prestige in language survival, such as Mufwene (2003).

Before reaching these conclusions, we have adopted both a qualitative and a quantitative approach. The qualitative approach consisted of analyzing the two agent-based models proposed using a simulation tool for the case of agents placed in a regular network. The results have allowed us to qualitatively compare the models to real situations of language contact, and to assess the role of bilingual users and of social structure in language survival. These situations include: the endangered situation of Algherese in North-West Sardinia, the revitalization of Quechua in Peru (both owing to the values of the parameter $s$, prestige), the resilience of Galician in its competition with Spanish in NW Spain, and the emergence of Yanito (a code-switching variety) in Gibraltar, these last two owing to very low and very high volatility regimes (high and low parameter $a$ ) respectively. Secondly, in the comparison between the Abrams-Strogatz Model and the Bilinguals Model, we have visualized how the formation of spatial linguistic domains is favoured by the presence of bilingual users, which define the linguistic boundaries between monolingual domains. Thirdly, both models exhibit different qualitative results in complex networks. On the one hand, we have shown how in a small-world network the presence of bilingual users leads to a faster extinction of one of the languages. On the other hand, in the Bilinguals model and in networks with community structure, we have seen how the social network gives rise to scenarios of language segregation (a special case of language coexistence), as is the case, for example, of Pennsylvania Dutch, which has survived in a segregated community, surrounded by speakers of English, with whom interaction is minimal.

The quantitative approach to the study of the modelling of language competition has been achieved by formally analyzing these models on different networks: fully connected networks (the simplest case), and complex random networks, where local effects arise because agents do not speak to every other agent but only to their neighbours in the social network. Findings indicate that: (a) the presence of bilingual agents (only present in the Bilinguals model) reduces the scenario of coexistence (language maintenance) substantially, as compared to the simpler Abrams-Strogatz model; (b) local effects in a complex random 
network reduce the coexistence scenario compared to the fully connected network, and strengthen the role of prestige, (c) spatial correlations between neighbours (regular network) reduce the domain of parameters for which coexistence is possible even further. In other words, we have found that local effects and bilingual agents reduce the possibility of having language contact situations in which two languages can coexist for long periods of time. However, it is very important to note that social networks with community structure, which are indeed much closer to real social networks than other networks considered in this study, make possible scenarios of segregated language coexistence for arbitrarily long periods of time when bilingual agents are considered in the modelling.

We have, then, quantitatively assessed the role of social network structure in language modelling and have seen that it indeed plays a significant role in the survival of languages in contact in agent-based models, in line with Milroy's claims (2001, for example) in sociolinguistics. When possible, we have qualitatively illustrated the results of the agentbased models studied with real life situations, but quantitative data and case studies are necessary in order that further conclusions can be reached. We believe that sociolinguistic case studies which take advantage of the use of languages in new technologies (online communities, e-mail networks, wikis, mobile phone networks, etc.), from which data on both language use and social network can be derived, can play a key role in the further understanding of language competition. The positive mutual benefits of simple models, like the ones presented in this paper, and such case studies will surely open new and promising lines of research.

University of the Balearic Islands Correspondence address: lucia.loureiro@uib.es

\section{References}

Abrams, Daniel M. \& Steven H. Strogatz. 2003. Modeling the dynamics of language death. Nature 424. 900.

Anderson, Philip W. 1972. More is different. Science 177. 393-396.

Auer, Peter (ed.). 1998. Code-Switching in Conversation. Language, Interaction and Identity. London \& New York: Routledge.

Auer, Peter. 1999. From codeswitching via language mixing to fused lects: Towards a dynamic typology of bilingual speech. International Journal of Bilingualism 3(4). 309-332.

Axelrod, Robert. 2006. Agent-based modeling as a bridge between disciplines. In Leigh Tesfatsion, Kenneth L. Judd (eds.), Handbook of Computational Economics Vol. 2: Agent-Based Computational Economics, 1565-1584. Amsterdam: North Holland/Elsevier.

Ayestaran Aranaz, Margarita \& Justo de la Cueva Alonso. 1974. Las familias de la provincia de Pontevedra (Galleguidad y conflicto lingüístico). Sevilla: Instituto de Ciencias de la Familia.

Baker, Colin \& Sylvia Prys Jones. 1998. Encyclopedia of Bilingualism and Bilingual Education. Clevedon: Multilingual Matters.

Ball, Philip. 2005. Critical Mass: How One Thing Leads to Another. London: Arrow Books.

Bot, Kees de \& Saskia Stoessel (eds.). 2002. Language change and social networks. [Special issue]. International Journal of the Sociology of Language 153. 
Bradley, David \& Maya Bradley (eds.). 2002. Language Endangerment and Language Maintenance. London/New York: Routledge Curzon.

Castellano, Claudio, Santo Fortunato \& Vittorio Loreto. 2009. Statistical Physics of Social Dynamics. Reviews of Modern Physics 81. 591-646.

Castelló, Xavier, Víctor M. Eguíluz \& Maxi San Miguel. 2006. Ordering dynamics with two non-excluding options: Bilingualism in language competition. New Journal of Physics 8. 308-322.

Castelló, Xavier, Riitta Toivonen, Víctor M. Eguíluz, Jari Saramäki, Kimmo Kaski \& Maxi San Miguel. 2007. Anomalous lifetime distributions and topological traps in ordering dynamics. Europhysics Letters 79. 66006-1-66006-6.

Castelló, Xavier, Riitta Toivonen, Víctor M. Eguíluz, Lucía Loureiro-Porto, Jari Sarmäki, Kimmo Kaski \& Maxi San Miguel. 2008. Modelling language competition: Bilingualism and complex social networks. In Andrew D.M. Smith, Kenny Smith \& Ramon Ferrer i Cancho (eds.), The Evolution of Language. Proceedings of the 7th International Conference (EVOLANG7), 59-66. Singapore: World Scientific Publishing Co.

Castelló, Xavier, Federico Vázquez, Víctor M. Eguíluz, Lucía Loureiro-Porto, Maxi San Miguel, Laetitia Chapel \& Guillaume Deffuant. 2011. Viability and Resilience in the Dynamics of Language Competition. In Gillaume Deffuant \& Nigel Gilbert (eds.), Viability and Resilience of Complex Systems. Concepts, Methods and Case Studies from Ecology and Society, 49-84. Boston/Dordrecht/London: Kluwer Academic Publishers.

Chapel, Laetitia, Xavier Castelló, Claire Bernard, Guillaume Deffuant, Víctor M. Eguíluz, Sophie Martin \& Maxi San Miguel. 2010. Viability and Resilience of Languages in Competition. PlosOne 5(1). e8681.

Chessa, Enrico. 2009. Why did you say you care about your language if you don't really? Language loyalty and language shift among the Catalan-speaking community of Alghero (Sardinia). Paper presented at the $42^{\text {nd }}$ Annual Meeting of the Societas Linguistica Europaea, University of Lisbon, 9-12 September.

Fishman, Joshua A. (ed.). 2001. Can Threatened Languages Be Saved? Reversing Language Shift Revisited: A 21st Century Perspective. Clevedon: Multilingual Matters.

Generalitat de Catalunya. 2004. Enquesta d'usos lingüístics a l'Alguer 2004. http://www6.gencat.net/llengcat/socio/docs/EULA2004.pdf (accessed 5 October, 2009).

Giles, Howard \& Philip M. Smith. 1979. Accommodation Theory: Optimal Levels of Convergence. In Howard Giles \& Robert St. Clair (eds.), Language and Social Psychology, 45-65. Oxford: Blackwell.

Grenoble, Lenore A. \& Lindsay J. Whaley (eds.). 1998. Endangered Languages: Current Issues and Future Prospects. Cambridge: Cambridge University Press.

Grenoble, Lenore A. \& Lindsay J. Whaley. 2006. Saving Languages: An Introduction to Language Revitalization. Cambridge: Cambridge University Press.

Hamers, Josiane F. \& Michel H.A. Blanc. 1989. Bilinguality and Bilingualism. Cambridge: Cambridge University Press.

Heller, Monica (ed.). 1988. Code-Switching: Anthropological and Sociolinguistic Perspectives. Berlin: Mouton de Gruyter.

Holmes, Janet. 2001 (2nd edn.). An Introduction to Sociolinguistics. London: Longman.

Labov, William. 1972. Sociolinguistic Matters. Philadelphia: University of Pennsylvania Press.

Levey, David. 2008. Language Change and Variation in Gibraltar. Amsterdam and Philadelphia: John Benjamins. 
Lipski, John M. 2008. Varieties of Spanish in the United States. Georgetown: Georgetown University Press.

Loreto, Vittorio \& Luc Steels. 2007. Social dynamics: Emergence of language. Nature Physics 3. 758-760.

Lozano, Sergi, Alex Arenas \& Ángel Sánchez. 2008. Mesoscopic structure conditions the emergence of cooperation on social networks. Plos One 3. e1892.

Manley, Marilyn S. 2008. Quechua language attitudes and maintenance in Cuzco, Peru. Language Policy 7. 323-344.

Milroy, Lesley. 1980. Language and Social Networks. Oxford: Blackwell.

Milroy, Lesley. 2001. Bridging the micro-macro gap: Social change, social networks and bilingual repertoires. In Jetske Klatter-Folmer \& Piet van Avermaet (eds.), Theories of maintenance and loss of minority languages, 39-64. Münster/New York: Waxmann.

Minett, James W. \& William S-Y. Wang. 2008. Modelling endangered languages: The effects of bilingualism and social structure. Lingua 118. 19-45.

Mira, Jorge \& Ángel Paredes. 2005. Interlinguistic similarity and language death dynamics. Europhysiscs Letters 69. 1031.

Monteagudo, Enrique \& Anxo Lorenzo (directors). 2005. A sociedade galega e o idioma. A evolución sociolingüística de Galicia (1992-2003). Santiago de Compostela: Consello da Cultura Galega.

Monteagudo, Henrique \& Antón Santamarina. 1993. Galician and Castilian in contact: historical, social and linguistic aspects. In Rebecca Posner \& John N. Green (eds.), Trends in Romance Linguistics and Philology. Volume V: Bilingualism and Linguistic Conflict in Romance, 117-173. Berlin \& New York: Mouton de Gruyter.

Moyer, Melissa G. 1993. Analysis of Code-Switching in Gibraltar. Barcelona: Publicacions de la Universitat Autònoma de Barcelona.

Moyer, Melissa G. 1998. Bilingual conversation strategies in Gibraltar. In Peter Auer (ed.), Code-Switching in Conversation. Language, Interaction and Identity, 215-234. London \& New York: Routledge.

Mufwene, Salikoko. 2001. The Ecology of Language Evolution (Cambridge Approaches to Language Contact 1). Cambridge: Cambridge University Press.

Mufwene, Salikoko. 2003. Language Endangerment: What Have Pride and Prestige Got to do With it? In Brian Joseph (ed.), When languages collide. Perspectives on Language Conflict, Language Competition and Language Coexistence, 324-346. Ohio: Ohio State University Press.

Mufwene, Salikoko. 2004. Language birth and death. Annual Review of Anthropology 33. 201-222.

Mufwene, Salikoko. 2008. Language Evolution. Contact, Competition and Change. London/New York: Continuum International Publishing Group.

Nettle, Daniel \& Suzanne Romaine. 2000. Vanishing Voices: The Extinction of the World's Languages. Oxford: Oxford University Press.

Onnela, Jukka-Pekka, Jari Saramäki, Jörkki Hyvonen, Gábo Szabó, David Lazer, Kimmo Kaski, János Kertèsz Kertèsz \& Albert-László Barabási. 2007. Structure and tie strengths in mobile communication networks. Proceedings of the National Academy of Sciences of the United States of America (PNAS) 104. 7332.

Poplack, Shana. 1980. Sometimes I'll start a sentence in Spanish Y TERMINO EN ESPAÑOL: toward a typology of code-switching. Linguistics 18. 581-618.

Rojo-Sánchez, Guillermo \& González-González, Manuel (directors.). 1995. Usos lingüísticos en Galicia. A Coruña: Seminario de sociolingüística da Real Academia Galega.

Romaine, Suzanne. 1989. Bilingualism. Oxford/New York: Blackwell. 
San Miguel, Maxi, Víctor M. Eguíluz, Raúl Toral \& Konstantin Klemm. 2005. Binary and multivariate stochastic models of consensus formation. Computing in Science and Engineering 7. 67-73.

Schelling, Thomas. 1978. Micromotives and Macrobehavior. New York: Norton.

Schulze, Christian, Dieter Stauffer \& Soeren Wichmann. 2008. Birth, survival and death of languages by Monte Carlo simulation. Communications in Computational Physics 3(2). 271-294.

Swann, Joan, Ana Deumert, Theresa Lillis \& Rajend Mesthrie. 2004. A Dictionary of Sociolinguistics. Edinburgh: Edinburgh University Press.

Toivonen, Riitta, Jukka-Pekka Onnela, Jari Saramäki, Jörkki Hyvönen, János Kertész \& Kimmo Kaski. 2006. A model for social networks. Physica A 371. 851-860.

Travers, Jeffrey \& Stanley Milgram. 1969. An Experimental Study of the Small World Problem. Sociometry 32. 425-443.

Trudgill, Peter. 1974. The Social Differentiation of English in Norwich. Cambridge: Cambridge University Press.

Trudgill, Peter. 1990. The Dialects of England. Oxford: Blackwell.

Vazquez, Federico, Xavier Castelló \& Maxi San Miguel. 2010. Agent Based Models of Language Competition: Macroscopic descriptions and Order-Disorder transitions. Journal of Statistical Mechanics: Theory and Experiment 2010. P04007.

Wang, William S.-Y. \& James W. Minett. 2005. The invasion of language: emergence, change and death. Trends in Ecology and Evolution 20(5). 263-269.

Warter, Per. 2009. Modelling processes and strategies in semicommunicative perception and production: The case of Scandinavia. In Bert Cornillie, José Lambert \& Pierre Swiggers (eds.), Linguistic identities, language shift and language policy in Europe, 215-228. Leuven: Peeters.

Wasserman, Stanley \& Katherine Faust. 1994. Social Network Analysis: Methods and Applications (Structural Analysis in the Social Sciences 8). Cambridge: Cambridge University Press.

Watts, Duncan J. \& Steven H. Strogatz. 1998. Collective dynamics of 'small-world' networks. Nature 393. 440-442.

Weinreich, Uriel. 1979 (5th edn.). Languages in contact. Findings and Problems. Paris/New York: Mouton. 


\section{FIGURES}

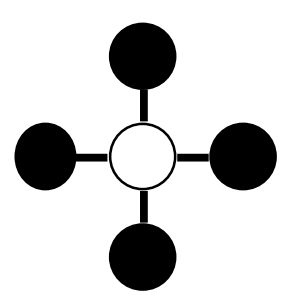

Figure 1: Interaction of an agent (white) with its neighbours (black).
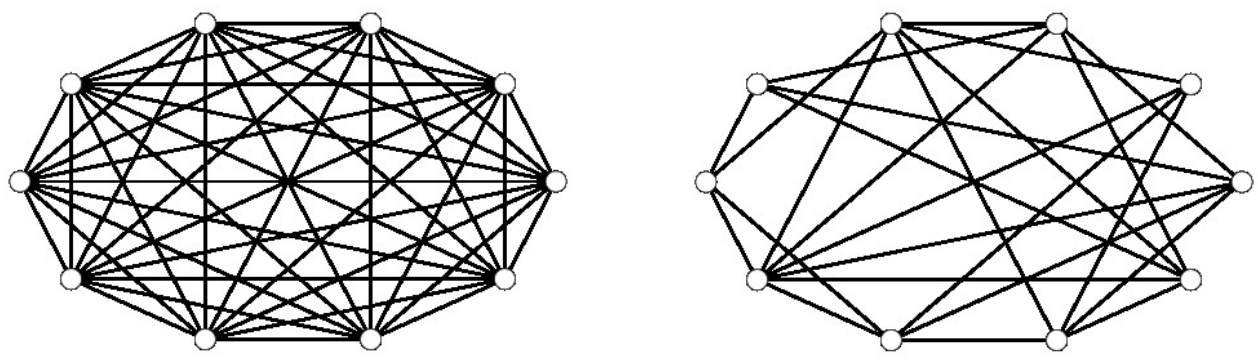

Figure 2: Fully connected network (left). Random network (right).
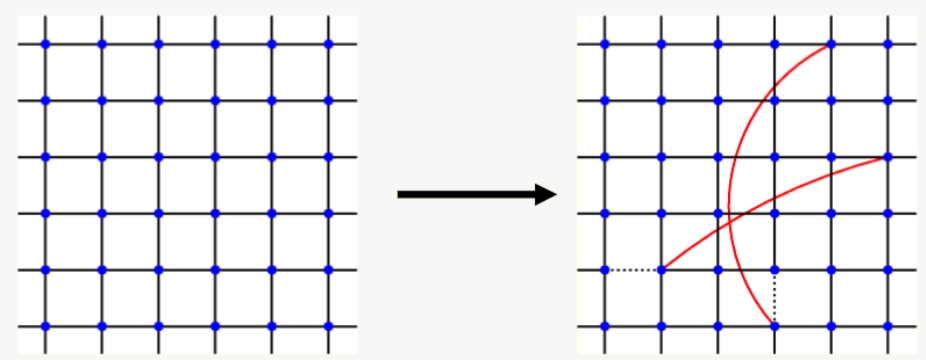

Figure 3: From a regular two-dimensional network (left) to a small world network (right), where the long range interactions have been explicitly shown. 


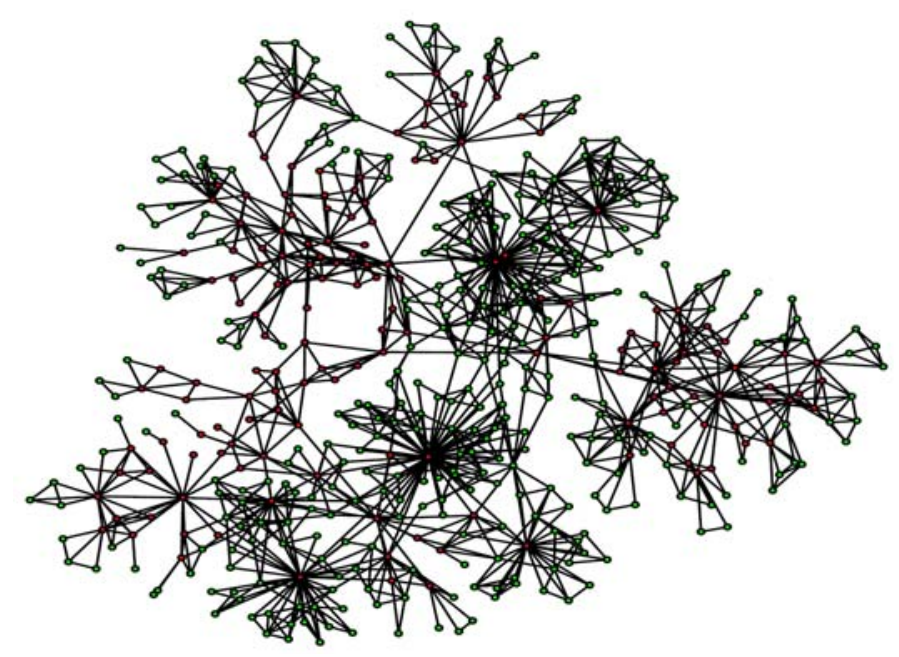

Figure 4: Network with community structure. For its construction, we use the algorithm described in Toivonen et al. (2006).

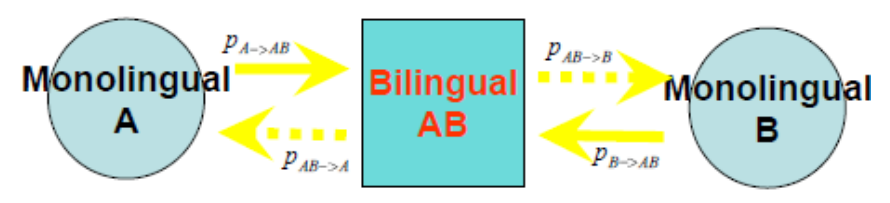

Figure 5: Bilinguals model of language shift.

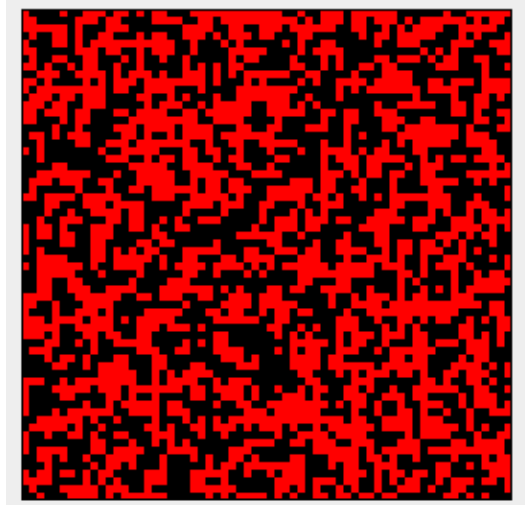

Abrams-Strogatz Model

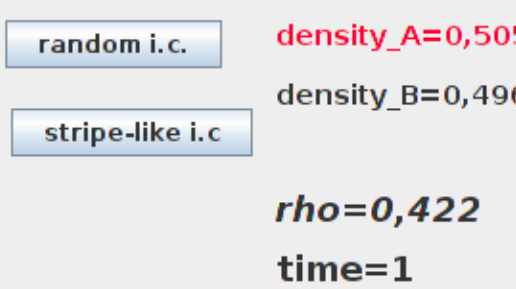

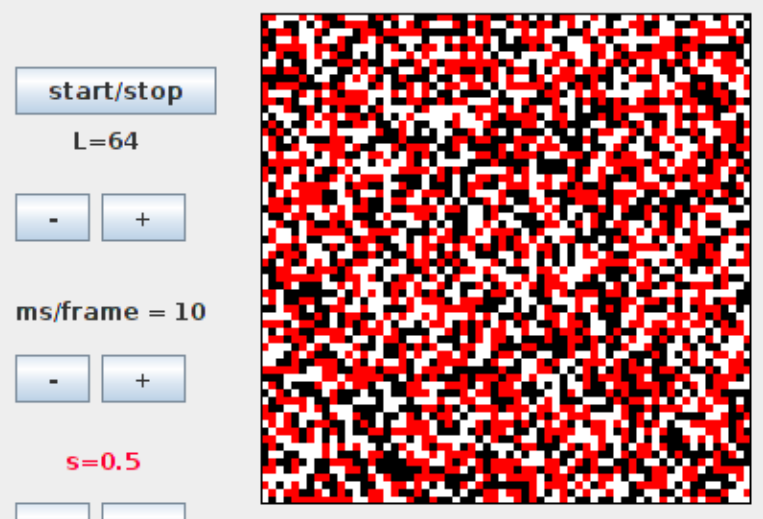

Bilinguals Model

$$
a=1.0
$$
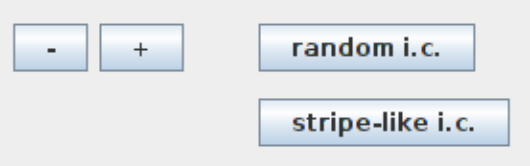

AB_init_domain

$$
\begin{aligned}
& \text { rho }=0,666 \\
& \text { time }=0
\end{aligned}
$$

density_A=0,341 density_B $=0,329$ density_AB $=0,33$

Figure 6: Applet: Abrams-Strogatz Model vs. Bilinguals Model. Language A (black), 
language B (grey), bilingual agents (white).
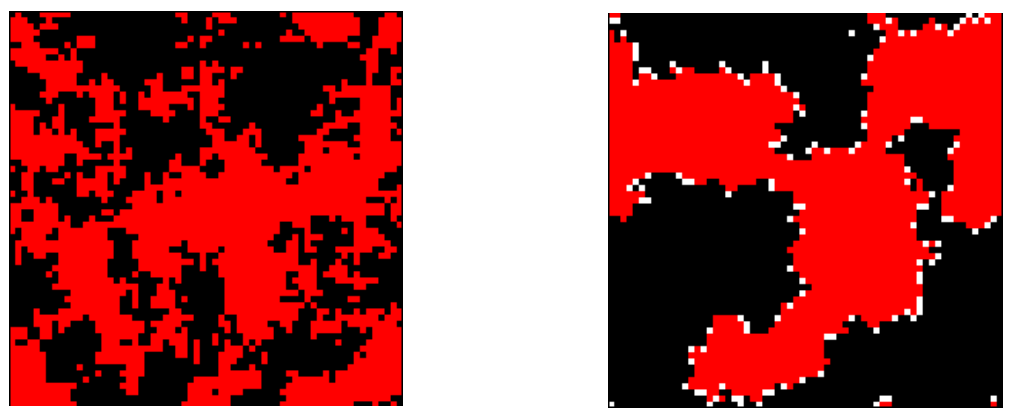

Figure 7: Abrams-Strogatz (left) and Bilinguals model (right). $s=0.5, a=1.0$. Bilingual agents and the formation of clearly defined linguistic domains. Language A (black), language B (grey), bilingual agents (white).
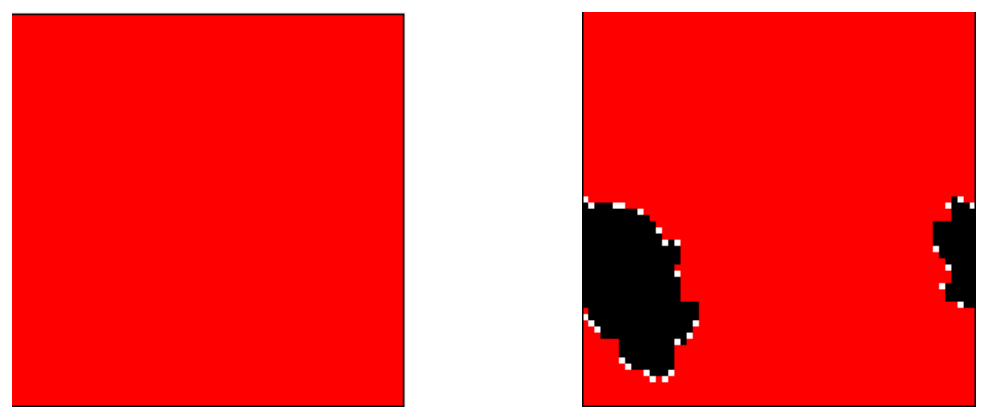

Figure 8: Abrams-Strogatz (left; time $=2197$ ) and Bilinguals model (right; time $=4274) . \mathrm{s}=0.5$, $\mathrm{a}=2$. Bilinguals preventing language death in non-volatile scenarios. Language A (black), language B (grey), bilingual agents (white).
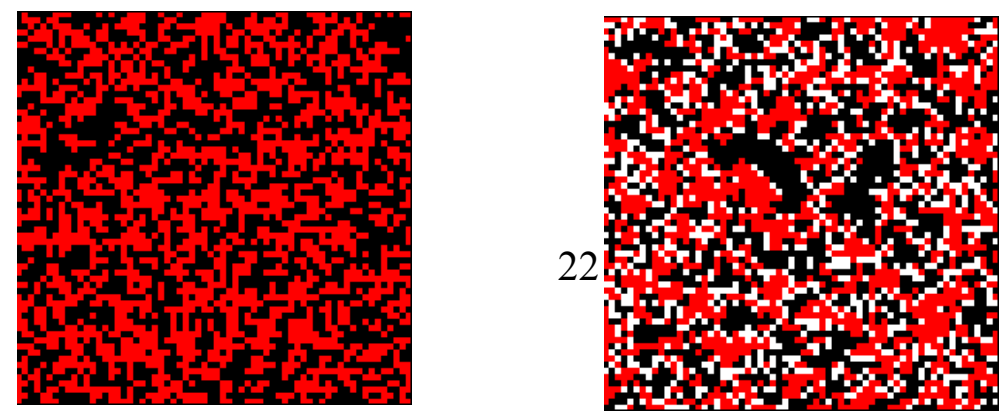
Figure 9: Abrams-Strogatz (left) and Bilinguals model (right). $\mathrm{s}=0.5, \mathrm{a}=0.1$, time $=8263$. Effects of high volatility on language survival. Language A (black), language B (grey), bilingual agents (white).

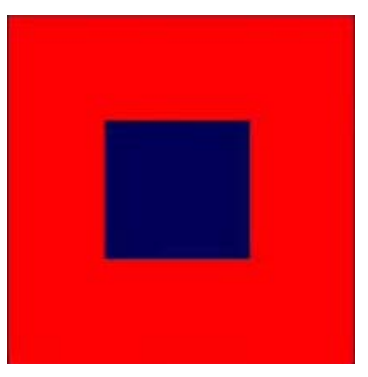

time $=0$

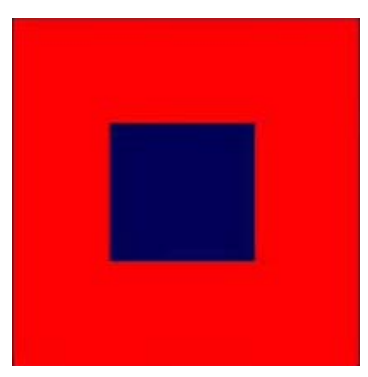

time $=0$

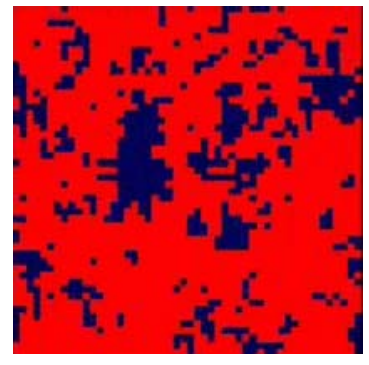

time $=50$

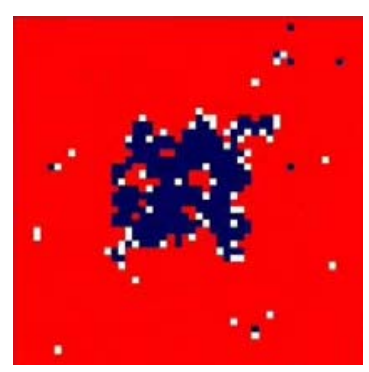

time $=50$

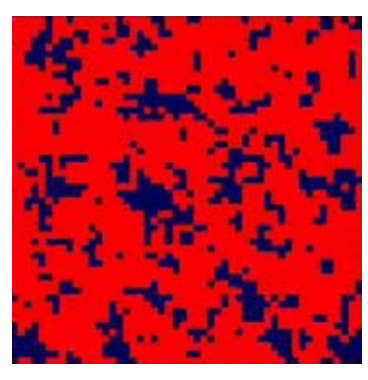

time $=150$

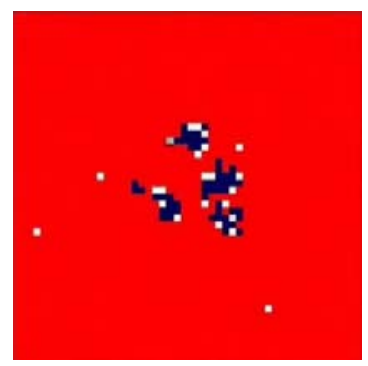

time $=150$ 
Figure 10: Snapshots of the Abrams-Strogatz (top) and the Bilinguals model (bottom) in a small-world network (projected in a two-dimensional space). A tenth of the links are longrange connections. Language A (black), language B (grey), bilingual agents (white). 

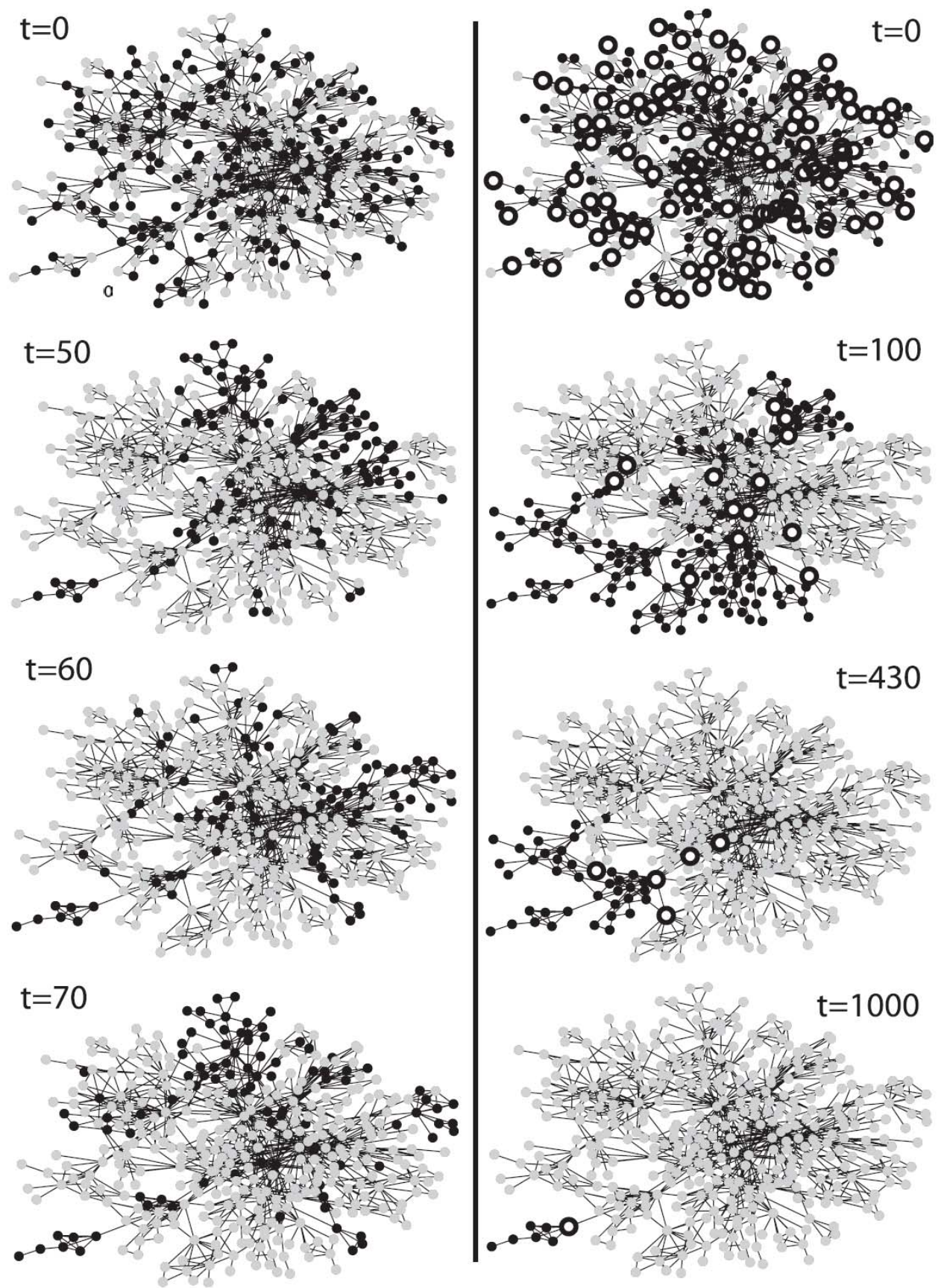

Figure 11: Snapshots of simulations for the Abrams-Strogatz model (left) and the Bilinguals model (right). Language A (black), language B (grey), and bilingual agents (white circled in black). (Figure from Castelló et al. 2007). 

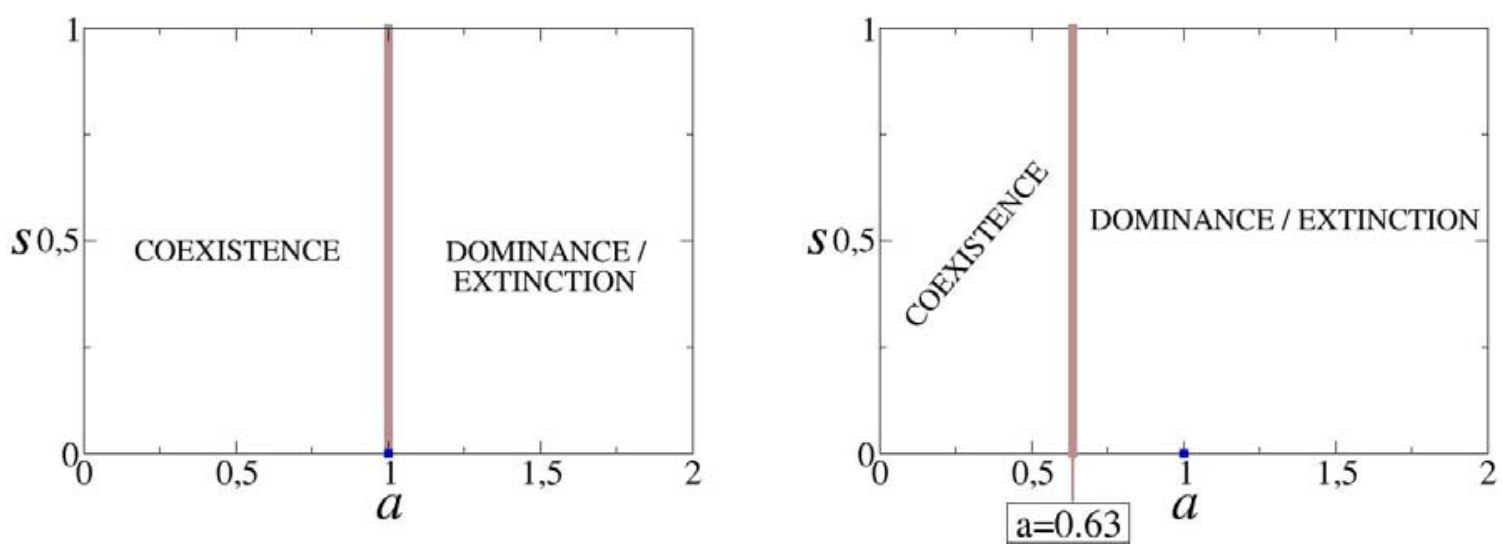

Figure 12: Stability diagram for the Abrams-Strogatz model (left) and the Bilinguals model (right), showing the final scenario of the model depending on the possible values of the model parameters, $a$ (X axis) and $s$ (Y-axis): coexistence and dominancelextinction.

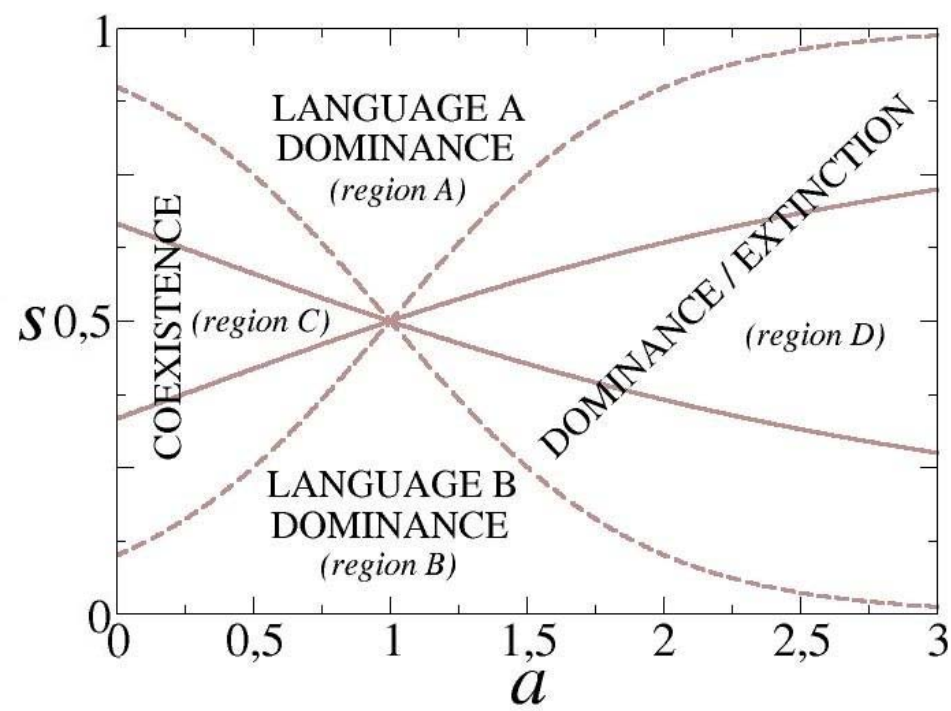

Figure 13: Stability diagram for the Abrams-Strogatz model in a random network with $\mu$ neighbours. $\mu=10$ (dashed grey lines); $\mu=3$ (solid grey lines). 
1 The authors wish to thank Víctor M. Eguíluz and Federico Vazquez for their indispensable contributions to earlier studies which made the present paper possible. In addition, for generous financial support, Xavier Castelló and Maxi San Miguel thank the Spanish Ministry for Science and Innovation and the European Regional Development Fund (grant FIS2007-60327, FISICOS), and Lucía Loureiro-Porto thanks the Autonomous Government of Galicia (INCITE grant 08PXIB204016PR) and the Spanish Ministry for Science and Innovation and the European Regional Development Fund (grants HUM2007-60706 and FFI2011-26693-C02-02). Thanks are also due to Riitta Toivonen, Jari Saramäki and Kimmo Kaski, for fruitful discussions.

2 Although the term tie is used in Sociolinguistics (cf. Swann et al. 2004: 283-284), in current social modelling the equivalent term is link.

3 Although status is the term Abrams and Strogatz have used to refer to prestige, it appears to us less appropriate for sociolinguistic studies, since in linguistics it usually refers to the degree of officiality of a language (e.g. official, co-official, etc.).

4 The term accommodation has been used in sociolinguistics (from Giles and Smith 1979 onwards) to refer to the "phenomenon where people adapt their language to the linguistic variety of the communication partner" (Warter 2009: 216), and it can be of different sorts (see Elordieta and Romera, this issue, for a case of prosodic accommodation of the Majorcan variety of Spanish to the Majorcan variety of Catalan).

5 Imitation here, in terms of modeling, is equivalent to agents shifting language proportionally to the fraction of neighboring agents using the other language.

6 Notice that the model we study (Bilinguals model) was essentially proposed by Minett and Wang in a working paper in 2005, based on their own remarks in Wang and Minett (2005). This working paper lead to the publication of a modified model in Minett and Wang (2008).

7 Notice that in this work, as a first approximation, we assume symmetrical volatility, i.e. agents exhibit the same degree of volatility for shifts from language A to language B as for shifts from language B to language A. Obviously, extensions of the models in which volatility (language loyalty) depends on the languages and the speakers (heterogeneous agents) are interesting future lines of research.

8 Available at http://ifisc.uib.es/research/complex/APPLET LANGDYN.html.

9 There actually exists an Algherese school (private evening courses), but the language is absolutely absent from other official schools.

10 Even though action is being taken to encourage the use of Catalan in the area, this is in favour of introducing Standard Catalan, rather than of restoring the use of Algherese (Chessa 2009).

11 It must also be noted that at this time Galician had still not recovered from the intense stigmatization suffered for three centuries (known as séculos escuros 'dark centuries', end $15^{\text {th }}$ c.-end $18^{\text {th }}$ c., cf. Monteagudo and Santamarina 1993: 121-123).

12 In addition to the emergence of code-switching varieties, high volatility of the speakers also prevents language death in real life situations in which the grammar and phonology of one of the languages is adapted to the grammar and phonology of the competing language, as is the case of Ingrian and Votic, as studied by Markus and Rozhanskiy, this issue.

13 This means that, although not explicitly shown, a fraction of the links connect distant nodes (see Figure 3-Right). 
${ }^{14}$ However, it can be shown that, as the difference in prestige increases, the most prestigious language becomes the dominant one for an increasing set of the possible initial configurations of the languages spoken by the agents. 